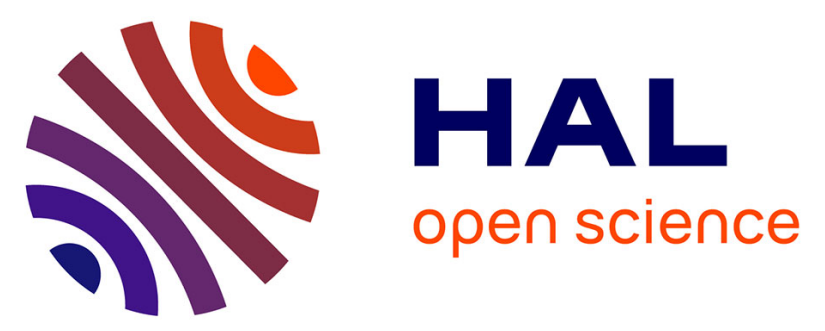

\title{
Assessment of Advanced RANS Models against Large Eddy Simulation and Experimental Data in the Investigation of Ribbed Passages with Passive Heat Transfer
}

\author{
Amir Keshmiri, Karim Osman, Sofiane Benhamadouche, Nima Shokri
}

\section{To cite this version:}

Amir Keshmiri, Karim Osman, Sofiane Benhamadouche, Nima Shokri. Assessment of Advanced RANS Models against Large Eddy Simulation and Experimental Data in the Investigation of Ribbed Passages with Passive Heat Transfer. Numerical Heat Transfer, Part B Fundamentals, 2016, 69 (2), pp.96 110. 10.1080/10407790.2015.1096641 . hal-01715660

\author{
HAL Id: hal-01715660 \\ https://hal.science/hal-01715660
}

Submitted on 22 Feb 2018

HAL is a multi-disciplinary open access archive for the deposit and dissemination of scientific research documents, whether they are published or not. The documents may come from teaching and research institutions in France or abroad, or from public or private research centers.
L'archive ouverte pluridisciplinaire HAL, est destinée au dépôt et à la diffusion de documents scientifiques de niveau recherche, publiés ou non, émanant des établissements d'enseignement et de recherche français ou étrangers, des laboratoires publics ou privés. 


\title{
Assessment of Advanced RANS Models against Large Eddy Simulation and Experimental Data in the Investigation of Ribbed Passages with Passive Heat Transfer
}

\author{
Amir Keshmiri $^{\mathrm{a}, \mathrm{b}, *}$, Karim Osman $^{\mathrm{b}}$, Sofiane Benhamadouche ${ }^{\mathrm{c}}$ and Nima Shokri ${ }^{\mathrm{d}}$
}

\begin{abstract}
${ }^{\text {a }}$ School of Engineering, Manchester Metropolitan University, Manchester M1 5G, UK.
${ }^{\mathrm{b}}$ School of Mechanical, Aerospace and Civil Engineering, The University of Manchester, Manchester M60 1QD, UK.

${ }^{\mathrm{c}}$ Électricité de France R\&D Division, Fluid Mechanics, Energy and Environment Department, 6 Quai Watier, 78401 Chatou Cedex, France.

${ }^{\mathrm{d}}$ School of Chemical Engineering and Analytical Science, University of Manchester, Manchester M60 1QD, UK.

* Corresponding Author: Tel: +44 (0) 161247 1695; E-mail: a.keshmiri@mmu.ac.uk
\end{abstract}

Short Title: RANS and LES of Ribbed Channels with Heat Transfer

\section{ABSTRACT}

Rough surfaces are widely used to enhance convective heat transfer by the promotion of higher turbulence levels. The present paper reports simulations of the flow and heat transfer in a $2 \mathrm{D}$ ribroughened passage using a number of advanced Reynolds-Averaged Navier-Stokes (RANS) turbulence models including Eddy-Viscosity Models (EVM) and a Reynolds Stress Model (RSM). Large Eddy Simulation (LES) is also conducted and results are compared against experimental measurements. In addition, the effects of rib thermal boundary condition on heat transfer are also investigated. In the present work, the blockage ratio of the transversely-mounted rectangular ribs is $10 \%$ and the rib pitchto-height ratio of 9 is selected. The Reynolds number, based on the channel bulk velocity and hydraulic diameter, is 30,000. The RANS-based turbulence models investigated here are the ' $k-\omega-S S T$ ', the ' $v^{2}-f$ ', the ' $\varphi-f$ ' and the 'Elliptic Blending RSM'. All computations are undertaken using the commercial and industrial CFD codes, 'STAR-CD' and 'Code_Saturne', respectively. Of all the models, the LES predictions were found to be in the best agreement with the experimental data, while the $k-\omega-S S T$ and EB-RSM returned the least accurate results. 
Keywords: Eddy-Viscosity Models, Heat Transfer, Large Eddy Simulation, RANS, Nuclear Reactor Core, Rib-Roughness, Thermal-Hydraulics, Turbulence Modelling.

\section{NOMENCLATURE}

A Cross-sectional area of the channel

$b \quad$ Rib width

$c_{f} \quad$ Local friction coefficient

$C_{p} \quad$ Pressure coefficient, $\left(p-p_{\text {ref }}\right) /\left(0.5 \rho U_{b}^{2}\right)$

$C_{\mu} \quad$ Coefficient in the turbulent viscosity of $k-\mathcal{E}$ turbulence models

$D_{e} \quad$ Hydraulic diameter, $4 A / P$

H Channel height

$k \quad$ Height of the rib or turbulent kinetic energy

$L \quad$ Length scale or computational domain length

$\mathrm{Nu} \quad$ Nusselt number, $\dot{q} D_{e} /\left(\lambda\left(T_{w}-T_{b}\right)\right)$

$p \quad$ Pressure

$P \quad$ Pitch or wetted perimeter

$\dot{q} \quad$ Wall heat flux

Re Reynolds number, $U_{b} D_{e} / v$

$T \quad$ Mean temperature

$T_{s} \quad$ Turbulent timescale

$U_{i}, u_{i} \quad$ Mean and fluctuating velocity components in Cartesian coordinates

$U_{\tau} \quad$ Friction velocity, $\left(\left|\tau_{w}\right| / \rho\right)^{1 / 2}$

$x \quad$ Streamwise coordinate

$y \quad$ coordinate or distance to the wall

$y^{+} \quad$ Dimensionless distance from the wall, $y U_{\tau} / v$

\section{Greek Symbols}

$\varepsilon \quad$ Dissipation rate of the turbulent kinetic energy

$\lambda$ Thermal conductivity

$\mu \quad$ Dynamic viscosity

$\mu_{t} \quad$ Turbulent viscosity

$v \quad$ Kinematic viscosity, $\mu / \rho$

$\theta \quad$ Fluctuating temperature

$\rho \quad$ Density

$\sigma_{k 1} \quad$ Coefficient in the SST model

$\sigma_{t} \quad$ Turbulent Prandtl number

$\tau_{w} \quad$ Wall shear stress

$\omega \quad$ Dissipation rate per unit of kinetic energy, $\varepsilon /\left(C_{\mu} k\right)$ 


\begin{tabular}{ll}
\multicolumn{2}{l}{ Subscripts } \\
$b$ & Bulk \\
$r e f$ & Reference \\
$t$ & Turbulent \\
$w$ & Wall
\end{tabular}

Additional symbols are defined in the text.

\section{INTRODUCTION}

For many years, rough surfaces have been one of the most common methods for convective heat transfer augmentation through increasing turbulence levels. The penalty associated with such roughening is an increase in pressure loss. Despite numerous studies on heat transfer, turbulence and turbulent boundary layer in rough surface problems, the detailed physics of these flow problems are still a topic of research.

In the past few decades there have been several experimental studies of the rib-roughened surfaces including those of Webb et al. [1], Han et al. [2], Park et al. [3], Liou et al. [4], Okamoto et al. [5], Rau et al. [6], Iacovides et al. [7, 8], Krogstad et al. [9] and Coletti et al. [10], amongst others. In these experiments, the effects of various factors including rib pitch-to-height ratio $(P / k)$, rib-to-channel height ratio $(k / H)$, rib shape and Reynolds number were tested.

Detailed flow and heat transfer measurements were made by Rau et al. [6] in a square channel with ribs presenting a blockage ratio of $10 \%$ (Figure 1). The results of the local measurements were discussed for three different $P / k$ ratios (6, 9 and 12) in a one-side-ribbed channel (' $\left.1 \mathrm{~s}^{\prime}\right)$. Measurements for a twoside-ribbed (' $2 \mathrm{~s}$ ') channel were reported for $P / k=9$. Air was the working fluid, and the Reynolds number based on the bulk velocity and the hydraulic diameter was fixed at $R e=30,000$. The data of Rau et al. [6] will be used in the present work to validate the numerical simulations.

There have also been numerous attempts to numerically simulate rib-roughened channels. A number of those works used the Large Eddy Simulation (LES) approach including Ciafalo and Collins [11], Sewall et al. [12] and Ahn et al. [13], among others. However, the most widespread techniques adopted were based on solution of the Reynolds-Averaged Navier-Stokes (RANS) equations, where the choice of turbulence model plays a critical role in determining the accuracy of the simulations. Some of the numerical investigations of rib-roughened surfaces using RANS were carried out by Baughn and Yan [14], Baughn and Roby [15], Iacovides and Raisee [16, 17], Manceau et al. [18], Ooi et al. [19], Bredberg et al. [20], Raisee et al. [21], Ryu et al. [22], Keshmiri and Gotts [23] and Keshmiri [24], amongst others.

Iacovides and Raisee $[16,17]$ examined the capabilities of the low-Reynolds-number Launder and Sharma [25] model (LS) and second moment closures in predicting convective heat transfer in ribbed annular channels, pipes and plane channels. They showed that the most reliable results were obtained 
using the low-Reynolds-number second moment closures. The authors also obtained a more realistic variation of heat transfer levels in the separation region and by employing a differential form of the Yap length-scale correction term, originally introduced by Yap [26], in $\varepsilon$-equation.

Manceau et al. [18] applied the $v^{2}-f$ model to a number of test cases including a 2D periodic ribbedchannel. They concluded that the $v^{2}-f$ model is a good compromise between simplicity and accuracy for simulating separated flows. They also showed that the $v^{2}-f$ model is an accurate turbulence model especially in estimating the near-wall turbulence anisotropy which is essential for reproducing the correct levels of heat transfer.

Ooi et al. [19] carried out simulations of the flow and heat transfer in 3-dimensional rib-roughened ducts using the $v^{2}-f$ and Spalart-Allmaras (S-A) turbulence models; they compared their results with the experimental data of Rau et al. [6] and the $k-\varepsilon$ simulations of Chen and Patel [27]. Configurations with various geometrical parameters including pitch, rib height, and cavity depth were considered. It was shown that, while the $k-\varepsilon$ model severely underestimates heat transfer levels, the S-A model gave results that were closer to the experimental data, but nonetheless the computed values of $N u$ were still far from the measured values. The authors reported that heat transfer results generated by the $v^{2}-f$ model were closest to the experimental values of Rau et al. [6]. However, none of the above models could capture the secondary flow structure which consequently led to incorrect predictions of $\mathrm{Nu}$ on the heated side wall.

Bredberg et al. [20] modified the $k-\omega$ formulation in an attempt to improve its performance in recirculating flows. Comparison was made against the experimental data of Rau et al. [6] and three other EVMs including the $k-\varepsilon$ model of Abe, Kondoh and Nagano [28], the $k-\omega$ model of Wilcox [29], and the $v^{2}-f$ model of Lien and Kalitzin [30]. For the Nusselt number distribution, it was found that both their proposed model and the $v^{2}-f$ model gave reasonable predictions, while the Wilcox $k$ - $\omega$ model underpredicted the Nusselt number. Once again, they confirmed that a close connection exists between heat transfer and the predicted turbulence levels.

Recently, Ryu et al. [22] carried out a series of simulations using the $k$ - $\omega$ model of Wilcox [31] to obtain the resistance coefficient and the velocity profile for a turbulent flow in channels with 2D ribs and 3D blocks. Various rib configurations were tested including ribs with square, triangular, semicircular, and wavy cross-sections over a range of rib pitch and Reynolds numbers. It was found that the $k-\omega$ model can successfully capture essential features of the flow.

More Recently, Keshmiri and Gotts [23] tested the effects of various geometrical factors on heat transfer and friction coefficient using two low-Reynolds number turbulence models including the $k-\omega$ SST [32] and a variant of Durbin's $v^{2}-f$ formulations [33]. They concluded that the $v^{2}-f$ model generally returns more accurate results than the $k$ - $\omega$-SST turbulence closure. Moreover, Keshmiri [24] used the $v^{2}$ - 
$f$ and $k$ - $\varepsilon$ models to carry out various numerical sensitivity analyses including the accuracy of a $2 \mathrm{D}$ channel approximation of a 3D configuration.

Large Eddy Simulation technique, although more expensive, particularly at high hydraulic Reynolds numbers, seems to globally give very satisfactory results in the literature. One of the pioneering works in the present configuration to the author's knowledge is by Ciafalo and Collins [11]. They carried out LES based on the Smagorinsky model which showed the increase of heat transfer upstream the rib. Sewall et al. [12] and Ahn et al. [13] studied a configuration close to the present one but with ribs on lower and upper walls of the channel. They concluded that LES is an appropriate tool for the present configuration.

In the present study, the performance of four advanced RANS models and a Large Eddy Simulation are evaluated for a rib-roughened channel flow using a commercial and an industrial CFD codes, 'STAR-CD' and 'Code_Saturne', respectively. Details of the configuration used in this work are given in Section 4.

\section{COMPUTATIONAL CODES}

\subsection{Code_Saturne}

Code_Saturne [34] is the Electricité de France (EDF) in-house CFD tool for incompressible flows. It is based on an unstructured collocated finite-volume approach for cells of any shape with Rhie and Chow interpolation and a SIMPLEC algorithm for pressure correction. While using LES, a fully centred scheme is applied for the velocity components and the temperature. For this latter, a slope test which switches to a $1^{\text {st }}$ order upwind scheme is utilized to limit the overshoots. The time scheme is second order based on Crank-Nicolson/Adams Bashforth scheme (the diffusion is totally implicit whereas the convection is semi-implicit). While using RANS or URANS, a centred scheme with a slope test is used for the velocity components and the temperature and a first-order upwind scheme for the turbulent quantities. The time scheme is first order Euler in this case.

\subsection{STAR-CD}

The second code to be used here is 'STAR-CD' [35], a commercial unstructured CFD package. In common with Code_Saturne, the program solves the governing equations using a collocated finite volume approach. Similar to Code_Saturne, STAR-CD is a co-localized cell centred incompressible Navier-Stokes solver. In the present STAR-CD computations, the momentum and turbulence transport equations are discretized using second-order central differencing and first-order upwind differencing schemes, respectively. The energy equation is discretized using the 'Monotone Advection and Reconstruction Scheme' (MARS) [35, 36]. The SIMPLE algorithm is adopted for pressure-velocity correction. The simulations are run at steady-state conditions. 
It is worth noting that STAR-CD and Code_Saturne have recently been tested by Keshmiri et al. [37] in a benchmarking exercise to assess their performance in simulating two distinct heat transfer problems, both of which had direct relevance to nuclear reactor flows. Despite some differences in the numerical procedures used by each code, in all cross-code comparison tests, good agreement was obtained for velocity and temperature profiles between both codes.

\section{TURBULENCE MODELS}

In this section, brief descriptions of the turbulence models used here are given. Interested readers are referred to Keshmiri et al. [38] for more detailed information on the turbulence models and the codes used in the present paper.

\section{1. $k-\omega-S S T$ Model (STAR-CD)}

Advantages of both the $k-\varepsilon$ and $k-\omega$ models are combined in the Shear Stress Transport (SST) model of Menter [32]. Through a blending function, this model effectively uses the Low Reynolds Number (LRN) formulation of the $k$ - $\omega$ model in the boundary layer and a version of the $k$ - $\varepsilon$ model (usually the 'standard $k-\varepsilon$ model') in the free shear layer. This is based on the observations that the $k-\varepsilon$ model is much less sensitive to the free-stream value of $\varepsilon$ than the $k-\omega$ model is to $\omega$. Apart from this unique feature, the main differences between the standard $k-\omega$ model and the SST one are the following:

- The SST model includes a damped cross-diffusion derivative term, as well as a blending function, in the $\omega$-transport equation.

- The definition of the turbulent viscosity in the SST was modified to improve the prediction of the turbulent shear stress.

- The coefficients were modified to improve the overall performance of the model.

Note that the functions and coefficients of the $k-\omega-S S T$ model may be found in several textbooks and are not included here for the sake of brevity. However, it is worth noting that the $k$ - $\omega$-SST models implemented in STAR-CD uses the original version of $k-\omega$-SST model proposed by Menter [32] (except the value of $\sigma_{k l}$ in STAR-CD which is set to 0.85 instead of 0.5 ).

\section{2. $v^{2}-f$ Model (STAR-CD)}

Another model to be considered here is the $\overline{v^{2}}-f$ model (or simply ' $v^{2}-f^{\prime}$ ) which was originally proposed by Durbin [39] and was designed to handle near-wall and non-local effects in turbulent boundary layers. In this model, the conventional ad-hoc damping functions are replaced with a third transport equation for $\overline{v^{2}}$, where $v$ is the wall-normal component of the fluctuating velocity. The revised turbulent viscosity equation then becomes: 


$$
v_{t}=C_{\mu} \frac{v^{2}}{k} k T_{s}
$$

where $T_{s}$ is the integral time scale and is defined as

$$
T_{s}=\max \left[\frac{k}{\varepsilon}, C_{k T}\left(\frac{v}{\varepsilon}\right)^{0.5}\right]
$$

where $C_{k T}$ is a constant. In addition, an elliptic equation for $f_{22}$ (the redistribution term in the $\overline{v^{2}}$ equation) is included to account for near-wall and non-local effects.

Note that, the original version being unstable because of the boundary conditions, there are currently several $v^{2}-f$ formulations in the literature, however, the version implemented in STAR-CD is that given by Iaccarino [33]. Therefore, the interested reader is referred to Iaccarino [33] and STAR-CD user manual [35] for further details on the present formulation.

\section{3. $\varphi$ - f Model (Code_Saturne)}

Laurence et al. [40] developed a robust formulation of the $v^{2}-f$ model which was based on the original $v^{2}-f$ model proposed by Durbin [39]. This formulation has been shown to be more stable than the original one and has been implemented in Code_Saturne in order to be used in industrial studies. The idea behind this model is to solve an equation for the ratio of $v^{2}$ and $k$ (named $\varphi$ ) which modifies the wall asymptotic behaviour and thus increases the stability of the system. For the temperature equation, the Simple Gradient Diffusion Hypothesis (SGDH) is used with a turbulent Prandtl number set to $\sigma_{t}=1$ (note that in all the present STAR-CD computations, the turbulent Prandtl number is set to a constant value, $\sigma_{t}=$ $0.9)$.

\subsection{Elliptic Blending - Reynolds Stress Model (Code_Saturne)}

As noted earlier by Iacovides and Raisee [16, 17], the use of a low Reynolds second order closure performed quite well on the present test case. Manceau and Hanjalić [41] developed a new version of the second moment closure turbulence model of Durbin [42]. They noticed that the six relaxation variables of Durbin's original model essentially accounts for geometrical effect to modify the pressurestrain process as the wall is approached. Hence, Manceau and Hanjalić proposed to define this transition by a single non-dimensional variable, solution of an elliptic equation (so called 'Elliptic Blending'). The blending factor is used to switch between high Reynolds and near-wall models for the scrambling term and the dissipation rate. The high Reynolds model is based on the SSG model [43]. The turbulent heat fluxes are solved using a transport equation which also uses the concept of elliptic blending (EB-DFM for Elliptic Bending - Differential Flux Model, see Dehoux [44]). 


\subsection{Large Eddy Simulation (Code_Saturne)}

The sub-grid scale tensor is modelled using the dynamic Smagorinsky model based on Germano et al. [45] identity and Lilly [46] minimization.

For the present LES procedure, an implicit (grid) filter is assumed, whereas an explicit filter is applied only to compute the dynamic constant. The width of the explicit filter is based only on the immediate neighbours of every cell (cells sharing a common face). The widely used approach of averaging the constant in the homogeneous (span-wise) direction in order to smooth it and to add stability is not utilized in the present work. The constant is capped between values of 0 and its value for the channel flow simulations. The code has been validated on several academic (decaying isotropic turbulence and channel flow) and industrial (T-junctions, tube bundles, etc.) test cases - see Benhamadouche [47]. The temperature equation uses a turbulent Prandtl number set to $\sigma_{t}=0.5$.

\section{GEOMETRY AND GRID}

\subsection{Geometry}

Based on the experimental data of Rau et al. [6], the rib height to channel hydraulic diameter ratio in the present simulations is $k / D_{e}=0.05$, and the blockage ratio $(k / H)$ is $10 \%$. The rib pitch-to-height ratio of $P / k=9$ is selected for the present analysis. Ribs are also assumed to have square cross-sections (i.e., $k=b$ ). The Reynolds number based on the bulk velocity and the hydraulic diameter is fixed at $R e=$ 30,000 and the Prandtl number is set to 0.71 .

The geometry considered here consists of a 2-dimensional channel, the lower wall of which is roughened by square ribs of height $k$. In STAR-CD simulations, the computational domain is of length $2 P$, i.e., it includes 2 ribs, while Code_Saturne uses a configuration with only 1 rib. Streamwise periodicity is assumed for all the computations. The domain is of height $H$ and the thermal boundary condition at both the lower and upper walls is set as uniform wall heat flux for STAR-CD computations and with an insulated rib for Code_Saturne computations. The effects of these thermal boundary conditions on the heat transfer results are investigated in Section 5.

It is worth noting that using a 2D configuration in the present work is justified based on the findings of Keshmiri [24] who showed that the flow over the centre-line of a 3D rib-roughened channel (such as the one used in Rau et al., 1998) can be represented by a 2D configuration with a relatively good accuracy.

\subsection{STAR-CD Computations}

The mesh used for STAR-CD computations is a structured Cartesian grid with approximately 160,000 computational cells. Since low-Reynolds-number turbulence models are employed, the grids were generated so as to be very fine near the wall (the wall-adjacent cell typically extends only to $y^{+} \leq$ $0.5)$. 


\subsection{Code_Saturne Computations}

RANS: The mesh used for Code_Saturne RANS computations is a structured Cartesian grid with approximately 54,000 computational cells. Several tests have been performed to ensure that the solution is mesh-independent. The $y^{+}$distribution is below 1 everywhere along the boundary.

LES: The present LES is well-resolved and uses a mesh containing 33 Million cells (160 cells in the span-wise direction). The maximum Courant number does not exceed 1 and the averaging is performed in time and space (30 flow passes based on the bulk velocity are used for time averaging).

\section{RESULTS AND DISCUSSION}

Figure 2 compares heat transfer results of the $k-\omega-S S T, v^{2}-f, \varphi-f$ and EB-RSM against the LES and the experimental data of Rau et al. [6]. Following Rau et al., all Nusselt number distributions for the ribbed duct calculations are normalized by the value associated with a smooth channel (the DittusBoelter equation):

$$
N u_{0}=0.023 \operatorname{Re}^{0.8} \operatorname{Pr}^{0.4}
$$

In Figure 2, it can be seen that the results of the $v^{2}-f$ model and LES are closest to the experimental data, while the $k-\omega-S S T$ and EB-RSM under-predict the rate of heat transfer especially in the recirculation area and therefore return the poorest predictions i.e., under-predict the magnitude of the wall heat flux. In the figure, it is also evident that different models predict different shapes for the heat transfer distribution; while the $\varphi-f$ and $v^{2}-f$ formulations tend to predict a uniform profiles, the LES predicts a rather skewed distribution towards the first rib. The $k-\omega-S S T$ and EB-RSM, however, both predict a distribution which is rather skewed towards the second rib.

Note that despite their contradicting predictions for the overall shape, LES and EB-RSM predict a sudden rise in heat transfer rate near the second rib which is consistent with the observations of earlier LES results reported in Ciafalo and Collins [11], Sewall et al. [12] and Ahn et al. [13]. This abrupt rise in heat transfer corresponds to the secondary vortex (recirculating bubble) formed in the vicinity of the downstream rib (this point is discussed further below in connection with Figure 5).

In addition to the above turbulence models, the non-linear EVM of Suga [48] was also tested for the present geometry (not included in the results), where severe numerical instability were encountered. Similar numerical instabilities have also been reported by [49] for mixed convection flows.

It is also worth mentioning that due to measurement limitations, the experimental data of Rau et al. [6] do not extend all the way to the faces of the ribs and therefore the accuracy of the simulations in these regions cannot be assessed by direct comparison. However, in the experiment data of Cho et al. [50] and Liou and Hwang [51] one can find such behaviour with a peak of the Nusselt number occurring just upstream the ribs. 
Streamlines obtained by all four RANS turbulence models as well as LES are shown in Figure 3. In this figure the main flow features are clearly visible; at the face of the first rib, a curved free shear layer is formed which reattaches within the inter-rib cavity. This is followed by the development of a new boundary layer which is accelerated by shear forces and separates once more before reaching the second rib. In the current configuration, the inter-rib cavity is mainly dominated by a large recirculation bubble which contains reversed flow in the near-wall region due to an adverse pressure gradient. [10]

In Figure 3 it can be seen that the $k$ - $\omega$-SST model and the LES/ $\varphi-f$ models return the largest and smallest separation bubbles, respectively. The former is probably due to a turbulent viscosity limiter that exists in the $k-\omega-S S T$ model which limits the shear stress when the production of $k$ exceeds its dissipation rate (by about an order of magnitude, for example). This limiter tends to eliminate the unrealistic buildup of eddy viscosity in the stagnation regions $[32,52]$.

Another interesting observation from Figure 3 is that the models with the poorest heat transfer predictions shown in Figure 2 (i.e., $k-\omega-S S T$ and EB-RSM) return the longest recirculation bubble. This over-prediction of the reattachment length results in an under-estimation of flow renewal in the cavity which could explain the poor predictions of the $k-\omega-S S T$ and EB-RSM in Figure 2. Furthermore, in Figure 3 , it is seen that the $\varphi-f$ and $v^{2}-f$ formulations return the smallest counter-rotating separation bubble near the second rib compared to the other models. Consequently, both models fail to capture the sudden increase of heat transfer which occurs in LES and EB-RSM within $8 \leq x / k \leq 8.5$ - see Figure 2.

Figure 4 shows the normalized streamwise velocity distributions at one-tenth of the rib height. The profile predicted by the LES is the closest to the experimental data, while $k-\omega-S S T$ has the worst prediction. In addition, all RANS and LES models and the experimental data clearly show a reattachment point $\left(U / U_{b}=0\right)$, except for the $k$ - $\omega$-SST model which indicates that the flow remains reversed at this elevation. The $k-\omega-S S T$ model therefore fails to predict flow renewal in the inter-rib cavity which is partly responsible for the under-prediction of heat transfer rate seen in Figure 2. The reattachment lengths predicted by the LES and the $\varphi-f$ model are the closest to that found by Rau et al. [6].

Results for the wall-normal velocity at rib height are presented in Figure 5. It can be seen that the results of the LES, $v^{2}-f$ and $\varphi-f$ models are in reasonably good agreement with the experimental data, with the LES being the closest. However, the EB-RSM and the $k-\omega-S S T$ model generally under-predict the magnitude of the wall-directed velocity. The poor performance of the EB-RSM and the $k$ - $\omega-S S T$ model in Figure 5 could also be anticipated from the streamlines shown in Figure 3, where these models returned the largest separation bubbles.

Normalized streamwise velocity profiles at two wall-normal planes, namely over the rib-top $(x / k=$ 0 ) and in the separation region $(x / k=4)$ are shown in Figure 6 and Figure 7, respectively. In Figure 6, it can be seen that all the models are in reasonable agreement with the measurements. The $k-\omega-S S T$ and 
$v^{2}-f$ models generally over-predict the magnitude of the velocity, while the LES, $\varphi-f$ and EB-RSM tend to predict smaller velocity magnitude.

At $x / k=4$, Figure 7 shows that all the models generally under-predict the magnitude of the velocity. However, further away from the wall $(y / H>0.2)$, the predictions of the $k-\omega-S S T$ and $v^{2}-f$ models are in better agreement with the data.

The size of the separation bubble predicted by each model is illustrated more clearly in the inset of Figure 7. It is shown that all the models yield longer separation bubble compared to the data. The results shown in the inset of Figure 7 are also consistent with the magnitude of the streamwise velocity in Figure 4 at $x / k=4$. It is worth mentioning that the experimental data shown in Figure 7 have been carefully extracted from a velocity vector plot reported in Rau et al. [6] and therefore the exact height at which $U / U_{b}=0$ was not possible to identify, hence not shown in this figure.

Attention is turned next to the inter-rib pressure distribution. Impingement on the upstream face of the rib leads to high static pressure, while there is a low pressure zone downstream of the rib. These effects can be seen in Figure 8, where the pressure coefficient distributions between the two ribs are plotted against $x / k$. Note that in this figure, $C_{p}$ in all cases is offset to the experimental value at $x / k=4.5$ (the centre of the inter-rib cavity). In Figure 8, the performance of the present numerical results can be assessed by splitting the inter-rib cavity into recirculation $(0.5 \leq x / k \leq 4.5)$ and recovery $(4.5 \leq x / k \leq 8.5)$ regions. Clearly most of the models (except the $\varphi-f$ model) fail to return a correct level of pressure in the recirculation region which is directly linked to the predicted size of the recirculation bubble (Figure 3) e.g., the longer the separation bubble, the lower the pressure magnitude. The predictions of the models tend to improve within the recovery region but still only the LES, EB-RSM and $v^{2}-f$ are in good agreement with the data.

A more detailed examination of the results shown in Figure 8 reveals that the LES and EB-RSM predict a sharp increase in the value of $C_{p}$ near the second rib, while the eddy-viscosity-based turbulence models (i.e., $k$ - $\omega$-SST, $v^{2}-f$ and $\varphi-f$ ) return quasi-linear distributions. Similar findings also emerged from the heat transfer results shown in Figure 2. These discrepancies clearly show the advantages of the LES and EB-RSM in simulating the counter-rotating recirculating flow ('secondary strain') near the second rib in comparison to linear eddy-viscosity models.

Furthermore, in the inset to Figure 8, the predicted pressure coefficient distributions are re-plotted but now $C_{p}$ is offset to the experimental value at $x / k=0.5$. The models return a wide range of pressure differences between $x / k=0.5$ and $x / k=8.5$, with the $v^{2}-f$ and EB-RSM predicting the maximum and minimum, respectively. The pressure difference predicted by the LES is clearly in very good agreement with the data.

Figure 9 shows the contours of the normalized turbulent kinetic energy for the $k$ - $\omega$-SST and $v^{2}-f$ models, which respectively represent one of the least- and most-accurate turbulence models tested in the 
present study. In general, both models predict that the maximum level of turbulent kinetic energy occurs around upstream and above the rib, at separation onset. A dramatic difference can be seen between the predictions of the models, especially around the ribs and the inter-rib cavity. The $v^{2}-f$ model predicts a stretched region with the highest turbulent kinetic energy levels which extends over the top of the rib, a shape which is consistent with the PIV measurements of Casarsa and Arts [53]. It is worth noting that the turbulent kinetic energy levels shown in Figure 9 can be related to the level of pressure drop predicted by each model; energy coming from the mean flow is an average pressure drop times (constant) mass flow rate which feeds into the turbulent kinetic energy and in turn is transferred into heat via the dissipation of turbulent kinetic energy.

\section{- Thermal Boundary Conditions of the Ribs}

In the present study, the application of two different thermal boundary conditions imposed on the ribs are investigated; in the first case, the thermal boundary condition on both the ribs and over the rib interval is one of the same uniform wall heat flux (Figure 10a), while in the second case, the ribs are insulated (adiabatic walls), as indicated in Figure 10 (b). This test provides some assessment of the uncertainties present in the experimental conditions. These uncertainties are usually associated with the measurement techniques, the rib and channel wall material properties and the presence of unsteady effects [54].

The $v^{2}-f$ formulation is used here to carry out the simulations to compare the effects of these two thermal boundary conditions. It was found that the thermal field was slightly affected especially in regions near the ribs. $\mathrm{Nu} / \mathrm{Nu} u_{0}$ distributions for both cases are shown in Figure 11. While both cases have similar heat transfer patterns, the case with insulated ribs produce slightly higher levels of heat transfer. It can also be seen that for the case with heated ribs, the heat transfer levels immediately downstream and upstream of the ribs are much lower than those of the insulated one. Similar results were also reported by Iaccarino et al. [54].

From the above findings, it can be concluded that the thermal boundary conditions on the ribs is relatively an insignificant parameter in the case studied here and affect heat transfer levels only in regions very close to the ribs, while naturally for a forced convection flow the dynamic field is not affected by the thermal boundary condition.

\section{CONCLUSIONS}

Numerical simulations of the flow and heat transfer in a 2-dimensional rib-roughened passage have been performed using $k-\omega-S S T, v^{2}-f, \varphi-f$, Elliptic Blending Reynolds Stress Model (EB-RSM) and Large Eddy Simulation (LES). Comparison was made against the experimental data of Rau et al. [6]. All simulations were undertaken using the commercial and industrial CFD codes, 'STAR-CD' and 'Code_Saturne', respectively. 
Of all the models, the LES predictions were found to be in the best agreement with the dynamic and thermal field data of Rau et al., while the $k-\omega-S S T$ and EB-RSM returned the least accurate results due to their poor wall heat flux predictions. The $v^{2}-f$ and $\varphi-f$ models also returned acceptable predictions, especially the $v^{2}-f$ model for the heat transfer.

It was also shown that the effects of some of the flow features such as the counter-rotating separation bubble near the second rib cannot be successfully simulated by linear eddy-viscosity models and were captured only by the LES and EB-RSM.

Furthermore, computations using the $v^{2}-f$ model showed that the thermal boundary condition imposed on the ribs has insignificant effects on the Nusselt number prediction. However, the local values of the Nusselt number in the regions close to the ribs are affected by the type of thermal boundary condition through convection.

Finally, it is also worth noting that one of the principal applications of the present work is to the ribroughened fuel pins of the UK fleet of Advanced Gas-cooled Reactors (AGRs). Although the results presented here are for a simple 2D-plane passage, this study would form a valuable precursor to the simulation of the more complex reactor geometries [see 55, for example].

\section{ACKNOWLEDGEMENTS}

The authors are pleased to acknowledge the contribution of their colleagues in the School of Mechanical, Aerospace and Civil Engineering (MACE) at the University of Manchester, especially Dr. M.A. Cotton, Professor D. Laurence and Dr. I. Afgan. The authors are also grateful to EDF for the use of its 'BlueGene P' supercomputer for the LES simulations.

\section{REFERENCES}

1. R. L. Webb, E. R. G. Eckert, and R. J. Goldstein. Heat transfer and friction in tubes with repeatedrib roughness, Int. J. Heat Mass Transfer, Vol. 14, pp. 601-617, 1971.

2. J. C. Han, L. R. Glicksman, and W. M. Rohsenow. An investigation of heat transfer and friction for rib-roughened surfaces, Int. J. Heat Mass Transfer, Vol. 21, pp. 1143-1156, 1978.

3. J. S. Park, J. C. Han, Y. Huang, S. Ou, and R. J. Boyle. Heat transfer performance comparisons of five different rectangular channels with parallel angled ribs, Int. J. Heat Mass Transfer, Vol. 35, No. 11, pp. 2891-2903, 1992.

4. T. M. Liou, Y. Y. Wu, and Y. Chang. LDV measurements of periodic fully developed main and secondary flows in a channel with rib-disturbed walls, J. Fluids Eng., Vol. 115, pp. 109-114, 1993. 
5. S. Okamoto, S. Seo, K. Nakaso, and I. Kawai. Turbulent shear flow and heat transfer over the repeated two-dimensional square ribs on ground plane, Trans. ASME J. Fluids Eng., Vol. 115, pp. 631-637, 1993.

6. G. Rau, M. Çakan, D. Moeller, and T. Arts. The effect of periodic ribs on the local aerodynamic and heat transfer performance of a straight cooling channel, ASME J. Turbomach., Vol. 120, pp. $368-375,1998$.

7. H. Iacovides, D. C. Jackson, H. Ji, G. Kelemenis, B. E. Launder, and K. Nikas. LDA study of flow development through an orthogonally rotating U-Bend of strong curvature and ribroughened walls, ASME Journal of Turbomachinery, Vol. 108, pp. 386-391, 1998.

8. H. Iacovides, D. C. Jackson, G. Kelemenis, and B. E. Launder. The measurement of local wall heat transfer in stationary U-ducts of strong curvature, with smooth and rib roughened walls, ASME Journal of Turbomachinery, Vol. 122, pp. 386-392, 2000.

9. P. A. Krogstad, H. I. Andersson, O. M. Bakken, and A. Ashrafian. An experimental and numerical study of channel flow with rough walls, J. Fluid Mech., Vol. 530, pp. 327-352, 2005.

10. F. Coletti, T. Maurer, T. Arts, and A. Di Sante. Flow field investigation in rotating rib-roughened channel by means of particle image velocimetry, Experiments in Fluids, Vol. 52, No. 4, pp. 10431061, 2012.

11. M. Ciafalo, and M. W. Collins. Large eddy simulation of turbulent flow and heat transfer in plane and rib-roughened channels, Int. J. Numer. Meth. Fluids Vol. 15, pp. 453-489, 1992.

12. E. A. Sewall, D. K. Tafti, A. B. Graham, and K. A. Thole. Experimental validation of large eddy simulations of flow and heat transfer in a stationary ribbed duct, International Journal of Heat and Fluid Flow, Vol. 27, pp. 243-258, 2006.

13. J. Ahn, H. Choi, and J. S. Lee. Large eddy simulation of flow and heat transfer in a rotating ribbed channel, International Journal of Heat and Mass Transfer, Vol. 50, pp. 4937-4947, 2007.

14. J. W. Baughn, and X. Yan. Local heat transfer measurements in square ducts with transverse ribs, Proceedings of ASME 28th National Heat Transfer Conference. Vol. 202, San Diego, USA, pp. 1-7, 1992.

15. J. W. Baughn, and J. L. Roby. Enhanced turbulent heat transfer in circular ducts with transverse ribs, Proceedings of ASME 28th National Heat Transfer Conference. Vol. 202, San Diego, USA, 1992

16. H. Iacovides, and M. Raisee. Recent progress in the computation of flow and heat transfer in internal cooling passages of turbine blade, Int. J. Heat Fluid Flow, Vol. 20, pp. 320-328, 1999. 
17. H. Iacovides, and M. Raisee. Computation of flow and heat transfer in two-dimensional ribroughened passages, using low-Reynolds-number turbulence models, Int. J. Numerical Methods for Heat and Fluid Flow, Vol. 11, pp. 138-155, 2001.

18. R. Manceau, S. Parneix, and D. Laurence. Turbulent heat transfer predictions using the $\mathrm{v}^{\wedge} 2-\mathrm{f}$ model on unstructured meshes, Int. J. Heat Fluid Flow, Vol. 21, pp. 320-328, 2000.

19. A. Ooi, G. Iaccarino, P. A. Durbin, and M. Behnia. Reynolds averaged simulation of flow and heat transfer in ribbed ducts, Int. J. Heat Fluid Flow, Vol. 23, pp. 750-757, 2002.

20. J. Bredberg, S. H. Peng, and L. Davidson. An improved k-w turbulence model applied to recirculating flows, Int. J. Heat Fluid Flow, Vol. 23, pp. 731-743, 2002.

21. M. Raisee, A. Noursadeghi, and H. Iacovides. Application of a non-linear k- $\varepsilon$ model in prediction of convective heat transfer through ribbed passages, Int. J. Heat Fluid Flow, Vol. 14, pp. 285304, 2004.

22. D. N. Ryu, D. H. Choi, and V. C. Patel. Analysis of turbulent flow in channels roughened by twodimensional ribs and three-dimensional blocks. Part I: Resistance, Int. J. Heat Fluid Flow, Vol. 28, pp. 1098-1111, 2007.

23. A. Keshmiri, and J. Gotts. Thermal-hydraulic analysis of four geometrical design parameters in rib-roughened channels, J. Numerical Heat Transfer; Part A: Applications, Vol. 60, pp. 305-327, 2011.

24. A. Keshmiri. Numerical sensitivity analysis of 3- and 2-dimensional rib-roughened channels, $J$. Heat Mass Transfer, Vol. 48, pp. 1257-1271, 2012.

25. B. E. Launder, and B. I. Sharma. Application of the energy dissipation model of turbulence to the calculation of flow near a spinning disc, Lett. Heat Mass Transfer, Vol. 1, pp. 131-138, 1974.

26. C. R. Yap. Turbulent heat and momentum transfer in recirculating and impinging flows, Dept. of Mech. Engineering, Faculty of Technology. Ph.D. Thesis, UMIST (now the University of Manchester), UK, 1987.

27. H. C. Chen, and V. C. Patel. Near-wall turbulence models for complex flows including separation, AIAA J., Vol. 26 (6), pp. 641-648, 1988.

28. K. Abe, T. Kondoh, and Y. Nagano. A new turbulence model for predicting fluid flow and heat transfer in separating and reattaching flows - I. Flow field calculations, Int. J. Heat Mass Transfer, Vol. 37, No. 1, pp. 139-151, 1994.

29. D. C. Wilcox. Comparison of two-equation turbulence models for boundary layers with pressure gradient, AIAA J., Vol. 31, pp. 1414-1421, 1993. 
30. F. Lien, and G. Kalitzin. Computations of transonic flow with the $\mathrm{v}^{2}$-f turbulence model, Int. J. Heat Fluid Flow, Vol. 22, pp. 53-61, 2001.

31. D. C. Wilcox. Turbulence Modeling for CFD, 2nd Edition, DCW Industries Inc., La Cañada, 1998.

32. F. R. Menter. Two-equation eddy-viscosity turbulence models for engineering applications, AIAA J., Vol. 32, pp. 1598-1605, 1994.

33. G. Iaccarino. Predictions of a turbulent separated flow using commercial CFD codes, J. Fluids Eng., Vol. 123, pp. 819-828, 2001.

34. F. Archambeau, N. Mechitoua, and M. Sakiz. A finite volume method for the computation of turbulent incompressible flows - Industrial applications, Int. J. on Finite Volume, Electronical edition: http://averoes.math.univ-paris13.fr/html, ISSN 1634(0655), Vol. 1(1), 2004.

35. CD-Adapco. STAR-CD Methodology, Version 4.02. 2006.

36. C. Hirsch. Numerical Computation of Internal and External Flows. Volume 2: Computational Methods for Inviscid and Viscous Flows: John Wiley \& Sons, 1990.

37. A. Keshmiri, J. C. Uribe, and N. Shokri. Benchmarking of Three Different CFD Codes in Simulating Natural, Forced and Mixed Convection Flows, J. Numerical Heat Transfer; Part A: Applications, Vol. 67, pp. 1324-1351, 2015.

38. A. Keshmiri, M. Cotton, Y. Addad, and D. Laurence. Turbulence Models and Large Eddy Simulations Applied to Ascending Mixed Convection Flows, Flow, Turbulence and Combustion, Vol. 89, No. 3, pp. 407-434, 2012.

39. P. A. Durbin. Near-wall turbulence closure modeling without damping functions, Theoret. Comput. Fluid Dynamics, Vol. 3, pp. 1-13, 1991.

40. D. R. Laurence, J. C. Uribe, and S. V. Utyuzhnikov. A robust formulation of the $\mathrm{v}^{2}$-f model, Flow, Turbulence and Combustion, Vol. 73, pp. 169-185, 2004.

41. R. Manceau, and K. Hanjalić. Elliptic blending model: A new near-wall Reynolds-stress turbulence closure, Phys. Fluids, Vol. 14, No. 2, pp. 744-754, 2002.

42. P. Durbin. A Reynolds-stress model for near-wall turbulence, J. Fluid Mech., Vol. 249, pp. 465498, 1993.

43. C. G. Speziale, S. Sarkar, and T. B. Gatski. Modelling the pressure-strain correlation of turbulence: an invariant dynamical system approach J. Fluid Mech., Vol. 227, pp. 245-272, 1991.

44. F. Dehoux. Modélisation statistique des écoulements turbulents en convection forcée, mixte et naturelle. PhD Thesis, Université de Poitiers - France, 2012. 
45. M. Germano, U. Piomelli, P. Moin, and W. Cabot. A dynamic subgridscale eddy viscosity model, Phys. Fluids, Vol. 3, No. 7, pp. 1760-1766, 1991.

46. D. Lilly. A proposed modification of the Germano subgrid-scale closure method, Phys. Fluids, Vol. 4, p. 633, 1992.

47. S. Benhamadouche. Large eddy simulation with the unstructured collocated arrangement, Dept. of Mechanical, Aerospace and Manufacturing Engineering. Ph.D. Thesis, UMIST (now University of Manchester), UK, 2006.

48. T. J. Craft, B. E. Launder, and K. Suga. Development and application of a cubic eddy-viscosity model of turbulence, Int. J. Heat Fluid Flow, Vol. 17, pp. 108-115, 1996.

49. A. Keshmiri, A. Revell, and H. Darabkhani. Assessment of a Common Non-Linear EddyViscosity Turbulence Model in Capturing Laminarization in Mixed Convection Flows, Numerical Heat Transfer; Part A: Applications, In-Press, DOI: 10.1080/10407782.2015.1069672 .

50. H. H. Cho, S. J. Wu, and H. J. Kwon. Local heat/mass transfer measurements in a rectangular duct with discrete ribs, ASME J. Turbomach. , Vol. 122, pp. 579-586, 2000.

51. T. M. Liou, and J. J. Hwang. Effect of ridge shapes on turbulent heat transfer and friction in a rectangular channel, Int. J. Heat Mass Transfer, Vol. 36, pp. 931-940, 1993.

52. L. D. Kral. Recent experience with different turbulence models applied to the calculation of flow over aircraft components, Progress in Aerospace Sciences, Vol. 34, No. 7-8, pp. 481-541, 1998.

53. L. Casarsa, and T. Arts. Aerodynamic performance investigation of a rib roughened cooling channel flow with high blockage ratio, 11th International Symposia on Applications of Laser Techniques to Fluid Mechanics Lisbon, Portugal, 2002.

54. G. Iaccarino, A. Ooi, P. A. Durbin, and M. Behnia. Conjugate heat transfer predictions in twodimensional ribbed passages, Int. J. Heat Fluid Flow, Vol. 23, pp. 340-345, 2002.

55. A. Keshmiri. Three-dimensional simulation of a simplified advanced gas-cooled reactor fuel elements, Nuclear Eng. Design, Vol. 241, pp. 4122-4135, 2011. 


\section{Figures Captions}

Figure 1. Schematic diagram of a rib-roughened surface.

Figure 2. Heat transfer distributions.

Figure 3. Comparison of streamlines and reattachment lengths for various models.

Figure 4. Streamwise velocity distributions at $y / k=0.1$.

Figure 5. Wall-normal velocity distributions at $y / k=1$.

Figure 6. Streamwise velocity profiles on the rib-top $(x / k=0)$.

Figure 7. Streamwise velocity profiles at $x / k=4$ plane. Legends are the same as in Figure 6.

Figure 8. Pressure coefficient distribution.

Figure 9. Contour plots of the turbulent kinetic energy for $P / k=9$; 1 s for $k-\omega-S S T$ and $v^{2}-f$ models.

Figure 10. The computational domains used with different rib thermal boundary conditions: (a) Heated ribs (b) Insulated ribs

Figure 11. Nusselt number distribution for two different rib thermal boundary conditions 


\section{Figures}

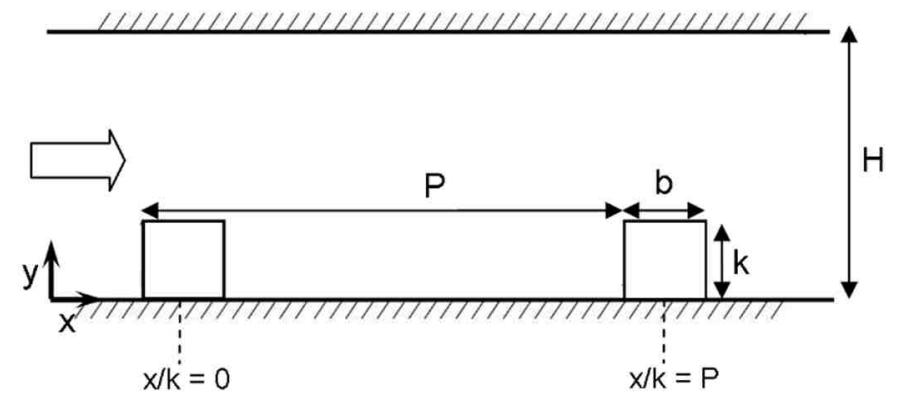

Figure 1. Schematic diagram of a rib-roughened surface. 


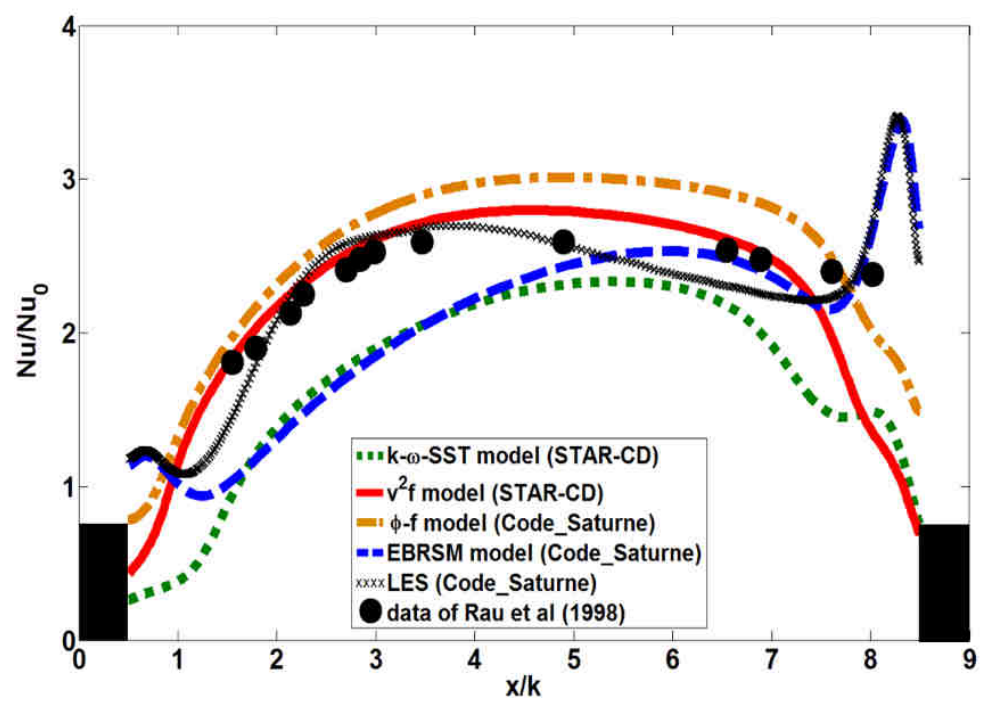

Figure 2. Heat transfer distributions. 

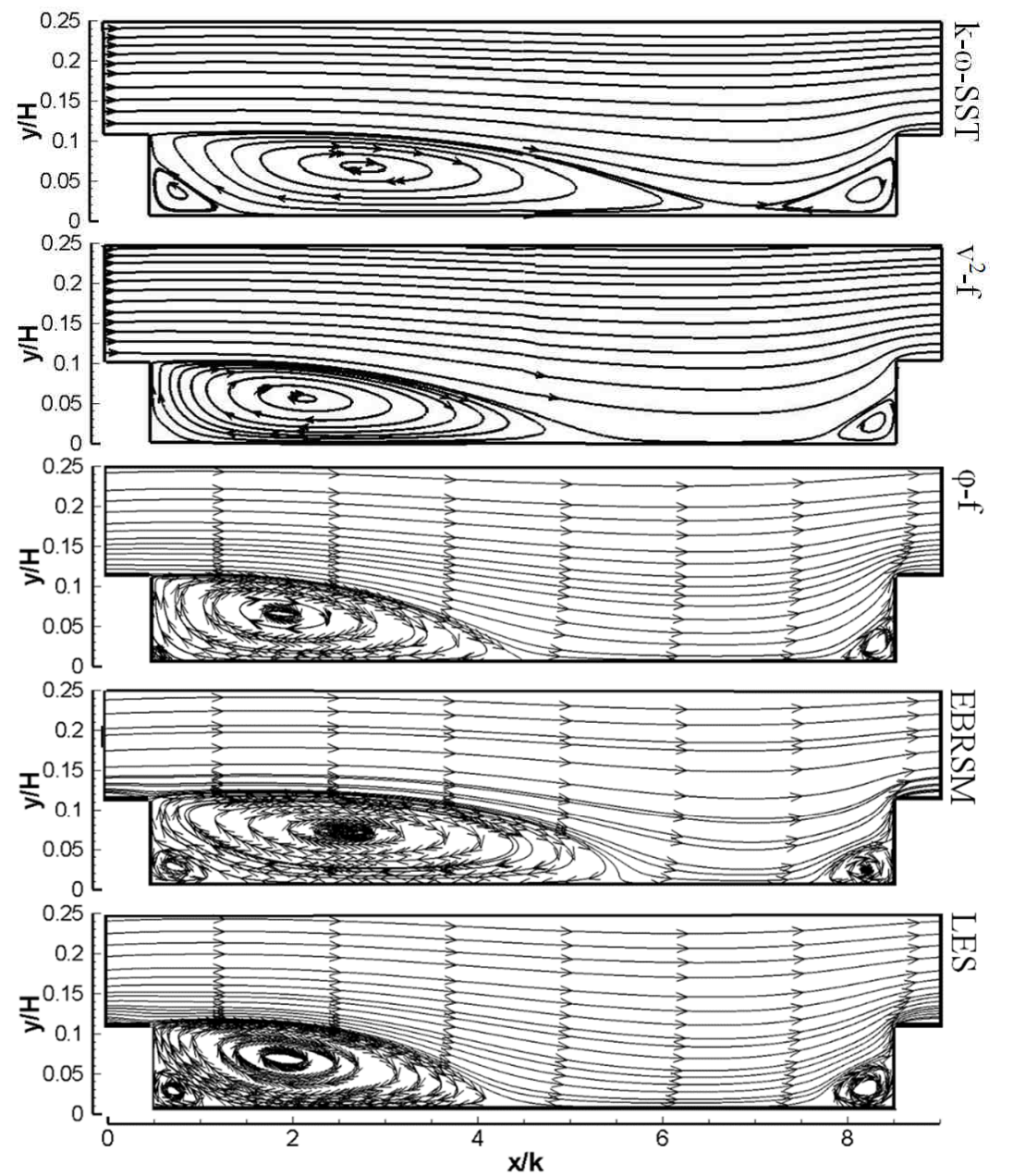

Figure 3. Comparison of streamlines and reattachment lengths for various models. 


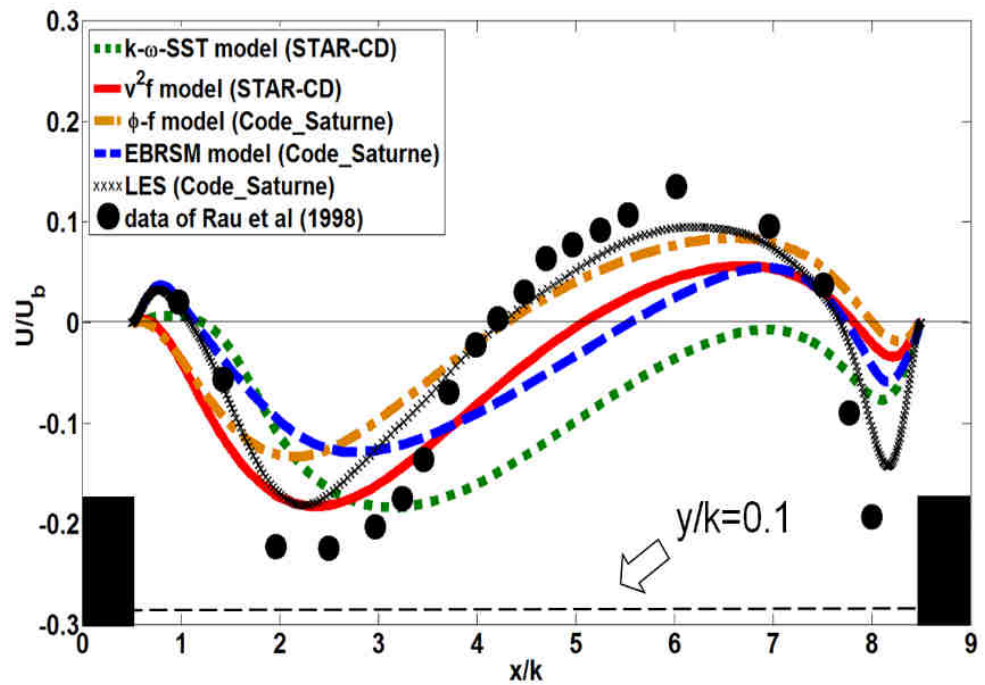

Figure 4. Streamwise velocity distributions at $y / k=0.1$. 


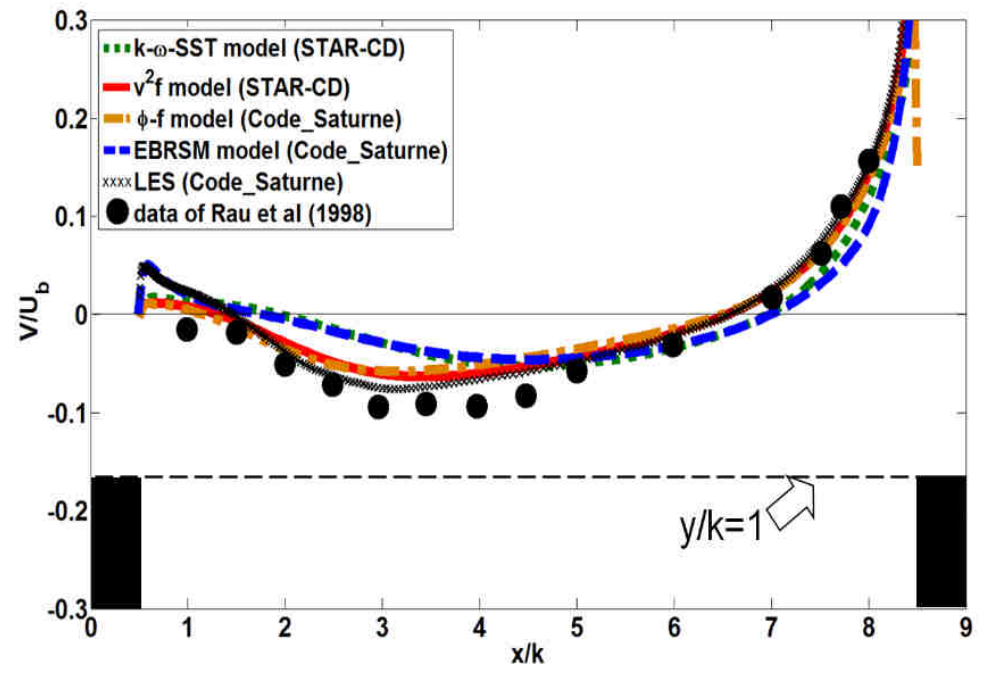

Figure 5. Wall-normal velocity distributions at $y / k=1$. 


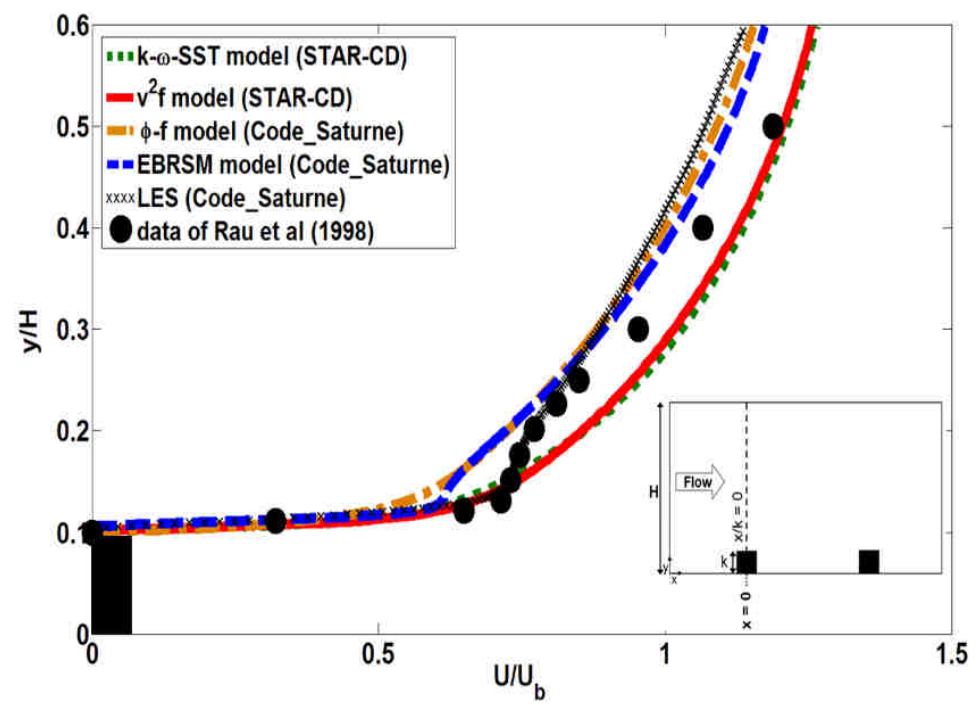

Figure 6. Streamwise velocity profiles on the rib-top $(x / k=0)$. 


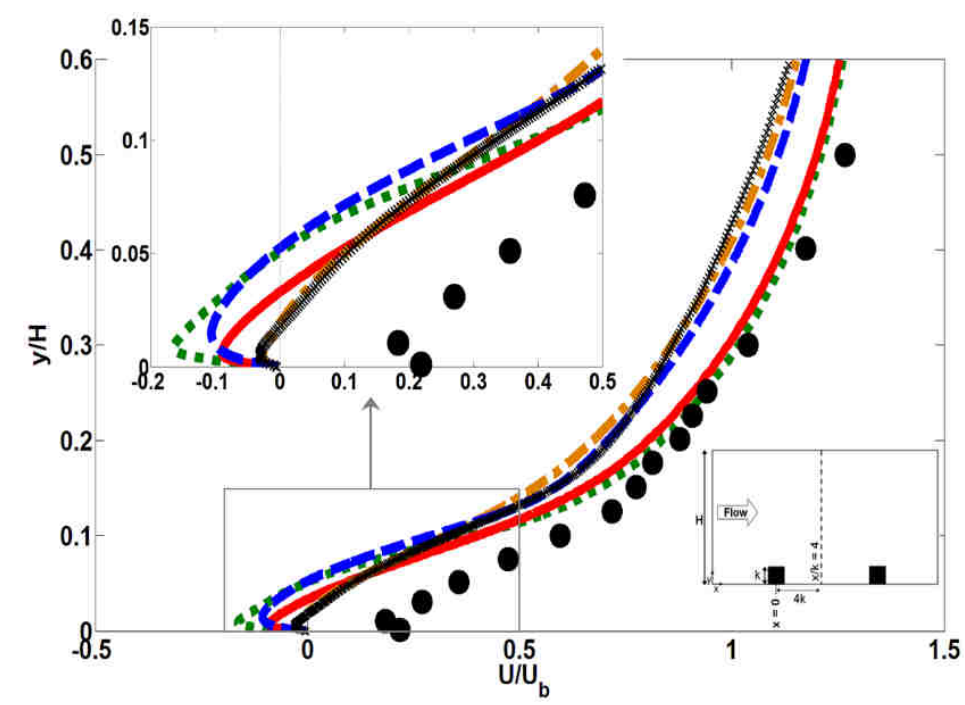

Figure 7. Streamwise velocity profiles at $x / k=4$ plane. Legends are the same as in Figure 6. 


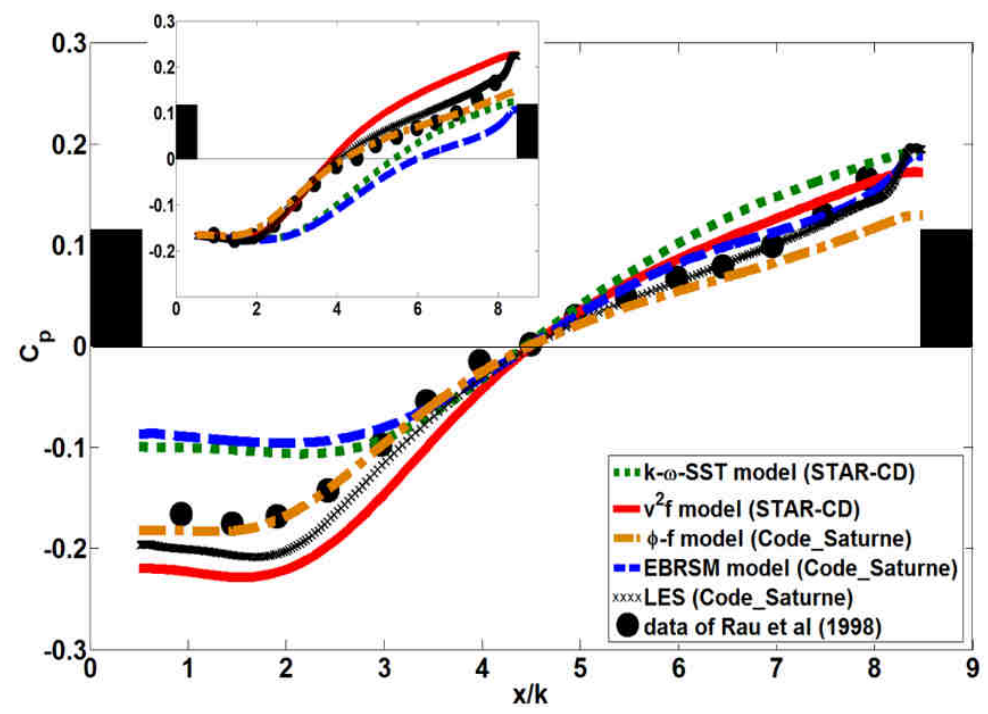

Figure 8. Pressure coefficient distribution. 

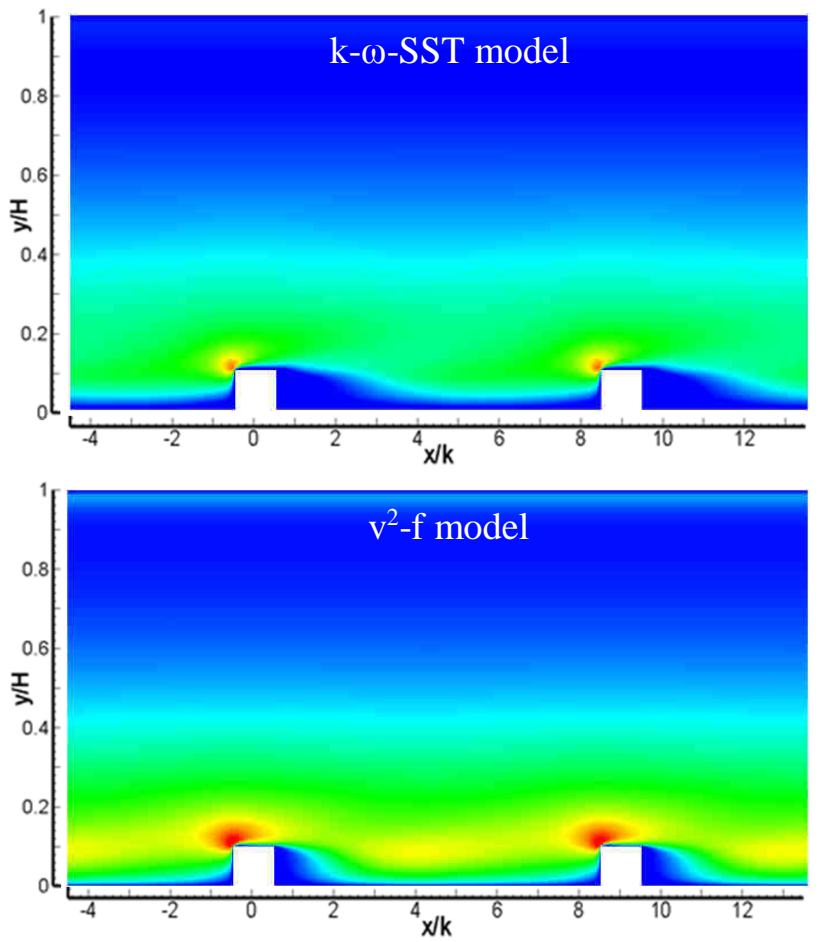

Turbulent kinetic energy $\left(k / U_{b}{ }^{2}\right)$ $\begin{array}{lllllllll}0.01 & 0.02 & 0.03 & 0.04 & 0.05 & 0.06 & 0.08 & 0.09 & 0.1\end{array}$

Figure 9. Contour plots of the turbulent kinetic energy for $P / k=9$; 1 s for $k-\omega-S S T$ and $v^{2}-f$ models. 


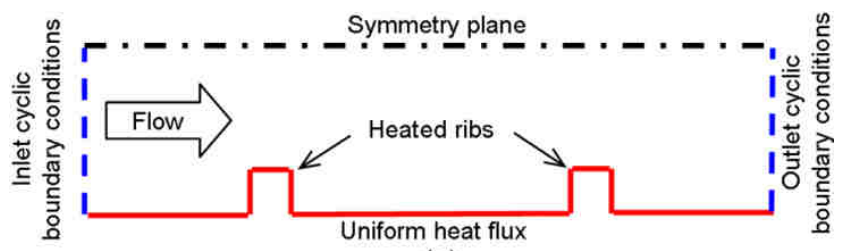

(a)

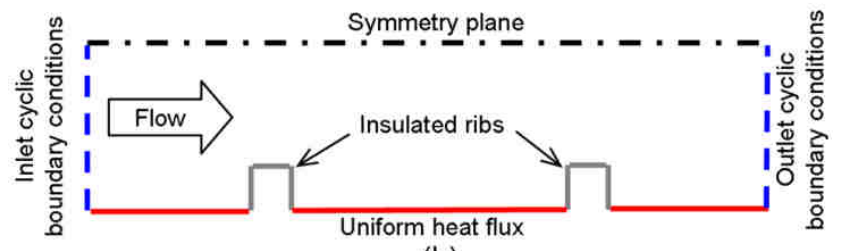

(b)

Figure 10. The computational domains used with different rib thermal boundary conditions: (a) Heated ribs (b) Insulated ribs 


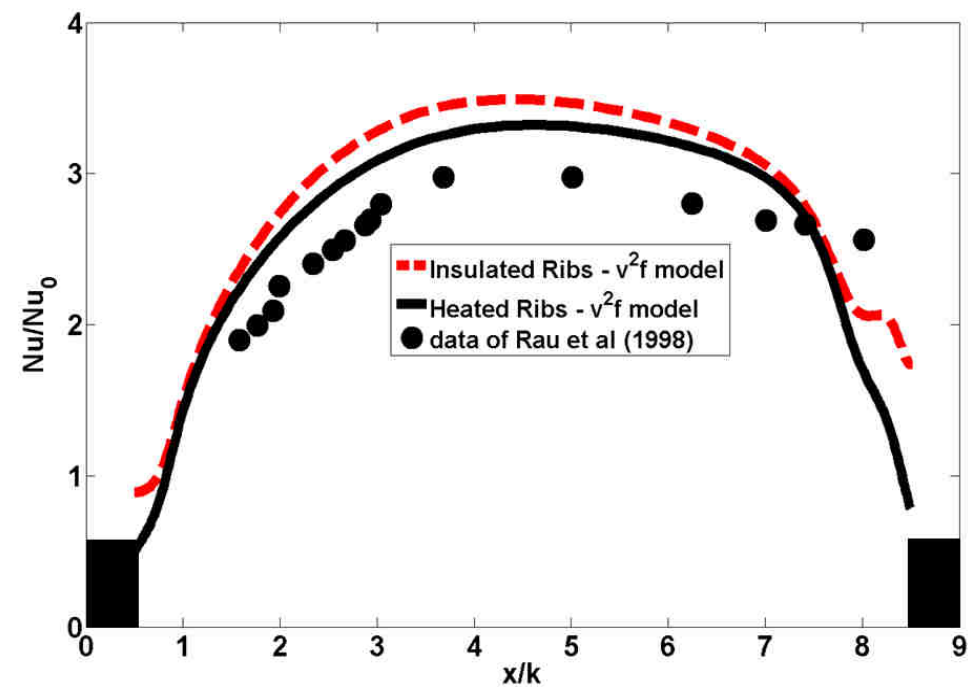

Figure 11. Nusselt number distribution for two different rib thermal boundary conditions 